\section{PWE-045 SHOULD ADENOMA DETECTION RATES BE AGE BASED?}

Xin Yi Choon*, lan Selby, Ross Sayers, Alistair McNair. Queen Elizabeth Hospital Woolwich, London, UK

\subsection{6/gutjnl-2019-BSGAbstracts.369}

Introduction Adenoma detection rate (ADR) is a measure of the quality of the colonoscopic examination, and in the UK a minimum target of $15 \%$ has been set for the whole population. Given the pathogenesis of adenomas, colonoscopists who examine a higher proportion of younger patients might be expected to encounter fewer adenomas, and as such not produce equivalent ADRs to those dealing predominantly with older patients. We set out to establish ADRs in patients of different age groups.

Methods We interrogated the endoscopy reporting system at a District General Hospital in South London over a 3-year period. We divided the patients into three age groups, and then determined the crude rate of polyp detection for each. From each age group we selected a sample of 100 consecutive patients who had polyps on their colonoscopy, and reviewed the histological diagnoses to determine the proportion of polyps which were clinically important i.e. adenomas, sessile or serrate lesions, and carcinomas. Chi-square testing was used to compare the different age groups for: the crude polyp detection rates, the rate of clinically important lesions in our samples, and the extrapolated number of clinically important lesions for the 3-year data set.

Results A total of 7928 colonoscopies were performed in this time period.

\begin{tabular}{|c|c|c|c|}
\hline & 2-9 year old & 4-9 year old & $6-0$ year old \\
\hline $\begin{array}{l}\text { Total number of colonoscopies } \\
\text { performed }\end{array}$ & 639 & 2519 & 4770 \\
\hline $\begin{array}{l}\text { Number of colonoscopies in which } \\
\text { polyps were detected }\end{array}$ & 102 & 605 & 1662 \\
\hline Crude rate of polyp detection & $\begin{array}{l}16.0 \% \text { p value } \\
(2-9 y o \text { vs. } 4- \\
9 y o)<0.001\end{array}$ & $\begin{array}{l}24.0 \% \text { p value } \\
\text { (4-9yo vs. } 6- \\
\text { Oyo })<0.001\end{array}$ & $\begin{array}{l}34.8 \% \text { p value } \\
\text { (2-9yo vs. } 6- \\
\text { 0yo }<0.001\end{array}$ \\
\hline $\begin{array}{l}\text { Number of adenomas, sessile or } \\
\text { serrated lesions, and carcinomas } \\
\text { in a sample of } 100\end{array}$ & 49 & 67 & 76 \\
\hline $\begin{array}{l}\text { Predicted rates of clinically } \\
\text { important polyps }\end{array}$ & $\begin{array}{l}7.8 \% \text { p value } \\
\text { (2-9yo vs. } 4- \\
9 \text { yo) }<0.001\end{array}$ & $\begin{array}{l}16.1 \% \text { p value } \\
(4-9 y o \text { vs. } 6- \\
\text { 0yo })<0.001\end{array}$ & $\begin{array}{l}26.5 \% \text { p value } \\
\text { (2-9yo vs. 6- } \\
\text { 0уо })<0.001\end{array}$ \\
\hline
\end{tabular}

Conclusions Our data suggests there is a significant difference in ADRs in different age groups, and that clinically important polyps are more likely to be found in older people. This adds to the body of evidence that ADRs increase with age. Future key performance indicators for colonoscopies should take this into account.

\section{PWE-046 GI SIDE EFFECTS OF CANCER TREATMENT: ARE WE MAKING ANY PROGRESS?}

A Faisal* , W Baber, Z Rana, J Andreyev. United Lincolnshire Hospitals Trust, Lincoln, UK

\subsection{6/gutjnl-2019-BSGAbstracts.370}

Introduction In 2012 the BSG with the Association of Coloproctology and others published guidance on the optimal management of acute and chronic GI toxicities of cancer treatments. A RCT (Lancet 2013) showed that targeted interventions delivered by a nurse or gastroenterologist can make a significant difference to those with chronic toxicity. The largest single group of people affected are those treated for colorectal cancer. Follow-up after colorectal cancer treatment is increasingly devolved to junior or paramedical staff and largely focuses on possible recurrence. This study investigated how toxicity after colorectal cancer is assessed and managed in a large district hospital.

Methods Outpatient clinic letters and inpatient discharge letters of a random selection of patients diagnosed with a new primary colorectal cancer during 2017, treated with curative intent and with at least one follow up appointment were audited retrospectively.

Results 462 patients were discussed at the colorectal MDT in 2017. Notes of 252 patients, 54\% men $(n=136)$ were scrutinised. Of these, 54\% ( $n=145$ age range $2-8$ years $)$ were treated with curative intent. The site of the primary cancer was anus $1 \% \quad(n=2)$, rectum $34 \% \quad(n=49)$, sigmoid $16 \%$ $(\mathrm{n}=23)$, left colon $5 \%(\mathrm{n}=7)$, transverse $8 \%(\mathrm{n}=11)$, right colon 35\% $(n=51)$ and appendix 1\% $(n=2)$. 79\% $(n=114)$ had a one-year follow-up.

$65 \%(n=94)$ were treated with surgery alone. 26\% $(n=37)$ underwent surgery and adjuvant therapy (chemotherapy and/or radiotherapy). 5\% $(\mathrm{n}=8)$ had surgery and neoadjuvant (chemotherapy and/or radiotherapy). 3\% had chemotherapy and radiotherapy but no surgery $(n=5)$ and $1 \% \quad(n=1)$ were treated with polypectomy alone.

$19 \%$ were readmitted with complications of surgery $(n=28)$ - mean length of stay, 10 days. Only 50\% ( $n=73)$ of follow up letters documented a conversation about side effects; GI $39 \%(n=56)$ psychological $6 \%(n=8)$; sexual $1 \%(n=1)$; tiredness $12 \%(n=17)$; quality of life $8 \%(n=11)$; urinary incontinence $8 \%(n=12)$.

GI problems included frequency, urgency, loss of appetite, abdominal pain, weight loss, diarrhoea, rectal bleeding, faecal incontinence and nocturnal defecation. Only 22\% of patients $(n=16)$ were offered investigations other than to rule out recurrent cancer, $41 \%(n=30)$ were offered advice and only $22 \%(n=16)$ were offered follow up to see if this advice helped.

Conclusions Survival after colorectal cancer is improving rapidly. However, it is associated with frequent and predictable side effects. In our busy hospital trust, there is little evidence of systematic enquiry about side effects of cancer treatment or appropriate investigation and effective treatments being offered at follow-up. The lessons learnt during the UK's 10-year survivorship programme run by the Department of Health and MacMillan Cancer Support have not impacted clinical practice. 